\title{
COVID-19 : Providing Rehabilitation Care in the Time of Pandemic
}

\author{
Abu Hassan S.A \\ Department of Orthopaedics, International Islamic University Malaysia
}

\section{INTRODUCTION}

In the wake of COVID-19 infection in the world, it is more devastating when a developing country is affected. Fortunately, due to coordinated infection control measures in Malaysia, the national morbidity and mortality rate is kept low. As of May 6th 2020, 22 patients required intensive care and the mortality rate was $1.66 \% .^{1}$ The majority of patients contracted a milder form of the disease.

As the fight to treat and contain the infection is being carried out, another set of question emerges: what happens to the infected patients after acute illness? How severe are the long term pulmonary complications? How best can we facilitate physical and functional recovery while protecting the rehabilitation team? For effective rehabilitation, the damage to the pulmonary system needs to be fully understood.

Since the early phase of infection, there is a predilection for the lower lobe of the lungs to be affected as it is where the ACE 2 receptors, a COVID-19 binding site, are predominantly located. In milder cases, subpleural lesions were detected resulting from inflammation caused by pneumocyte destruction. Up to $75 \%$ of patients develop bilateral pneumonia. $^{3}$

Radiological changes of the lungs occurs within 7 days of onset of symptoms. Early infection manifests as ground glass opacity and consolidation. ${ }^{3,4}$ As the disease progresses and become widespread, multilobular consolidation become more conspicuous. ${ }^{4}$

Corresponding Author:

Dr. Salmah Anim binti Abu Hassan

Department of Orthopaedics, Traumatology

and Rehabilitation, Kulliyyah of Medicine

International Islamic University Malaysia,

Kuantan Campus, Bandar Indera Mahkota,

25200, Kuantan, Pahang

Tel No : +6012-5797406

Email : anim@iium.edu.my
Severe alveolar inflammation results in exudative acute lung injury with edema and infiltrates. Within 9 to 13 days, the majority of radiological changes showed consolidation. ${ }^{3}$ Recovery period with resolution of consolidation. Long lasting pulmonary damage and functional limitations are yet to be studied in COVID-19 survivors. However, long term follow up with MERS-CoV patients showed that up to $33 \%$ have radiological evidence of lung fibrosis. ${ }^{5}$

The approach to rehabilitation in COVID-19 patients must be timely and with necessary caution to benefit patients and protect the rehab team. Early exposure to rehabilitation is important to reduce morbidity, mortality and length of hospital stay. 6 Timely exposure to respiratory exercises and mobilization also enables patients to better understand and comply with therapy. This will assist rehab personnel in providing reinforcement of techniques later in the course of the disease.

To protect the rehabilitation team, mode of therapy is based on illness severity. Asymptomatic or mild cases should perform aerobic and deep breathing exercises. ${ }^{6,7}$ Other than the standard incentive spirometry, daily items like balloon inflation or bubble blowing may be used as a cheaper and more enjoyable alternative. Patients with pneumonia and increased secretions are advocated to perform active cycle breathing therapy (ACBT). ${ }^{6}$ It consists of 3 steps encompassing breathing control, thoracic expansion exercises and huffing, or forced exhalation. ${ }^{6}$

For patients with severe infections requiring oxygenation or ventilation, secretion management and proper positioning are the main techniques to improve pulmonary drainage. Closed suctioning should be performed in a negative pressure room. Appropriate Level 2 personal protective equipment (PPE) usage which are N95 mask, face shield, fluid resistant long sleeve gown, gloves and shoe cover cannot be overemphasized. ${ }^{7}$ If the patient is 
cooperative, early mobilization or aerobic activity as tolerated by the patient need to be encouraged. ${ }^{6,7}$

Worldwide, COVID-19 patients have restricted access to rehabilitation in order to reduce healthcare worker exposure and economize PPE usage. ${ }^{6,8}$ Pulmonary rehabilitation and prolonged close contact with patients increase the risk of disease transmission. Level 2 PPE, a resource which have become scarce in developed countries, may be a luxury in poorer regions despite its necessity.

Alternative methods, such as usage of printed materials and telerehabilitation, to disseminate information are currently employed to guide patients with milder form of illness for respiratory exercises. ${ }^{6}$ Telerehabilitation has become a vital tool to mitigate the spread of the virus by limiting healthcare worker contact with positive cases. $^{6,7,8}$ In rehab practice, videoconferencing with COVID-19 patients enables demonstration and subsequent review of exercise techniques. Telephone consultations also increase frequency of rehabilitation consultations. Most importantly, these forms of communication build rapport and maintain a personal touch with patients who are already anxious and isolated. Online materials especially videos for respiratory exercises are made widely available on social media platforms since the pandemic has started. ${ }^{?}$

Despite the obvious benefits of telerehabilitation, it has been sparingly used in previous emergencies, for example as reported by the Australian healthcare service during the 2019 bushfires. ${ }^{8}$ The big leap in change from traditional medical practice has many physicians skeptical of its efficacy. ${ }^{10,11}$ Clinicians are also wary regarding privacy issues on both sides during teleconsultation. Furthermore, technical factors in developing countries like lack of hardware and reliable internet connection may also be a hindrance. ${ }^{11}$

The COVID 19 pandemic has indeed forced the rehabilitation fraternity to change our practices and be more innovative in order to provide the best patient care while minimizing risk of transmission to the treating personnel.

\section{Conflict of Interest}

The author has no conflict of interest to declare.

\section{ACKNOWLEDGEMENT}

The author would like to express her appreciation for all of the emergency services, nurses, doctors, and other healthcare staff for their efforts to combat the COVID-19 pandemic.

\section{REFERENCES}

1. Abdullah NH. Press statement from the Director General of the Ministry of Health Malaysia $6^{\text {th }}$ May 2020. [Malay] Available at: www.moh.gov.my/index.php/pages/view/2019 -ncov-wuhan-kenyataan-akhbar. Accessed May 6,2020.

2. G.Li, X.He, L. Zhang et al. Assessing ACE2 expression patterns in lung tissues in the pathogenesis od COVID-19. Journal of Autoimmunity.Available at www.ajronline.org. Accessed April 16,2020.

3. J. Chen, T. Qi, L. Liu et al. Clinical progression of patients with COVID-19 in Shanghai, China. 2020. Journal of Infection. Available at https://www.journalofinfection.com/article/ S0163-4453(20)30119-5/fulltext. Accessed April 10,2020.

4. F. Pan, T. Ye, P.Sun et al. Time course of lung changes on chest CT during recovery from 2019 novel coronavirus (COVID-19) pneumonia. Radiology.2020.Available at https:// pubs.rsna.org. Accessed Apr 12, 2020.

5. Hosseiny M.,Kooraki S., Gholamrezanezhad A. et al. Radiology perspective of Coronavirus Disease 2019 (COVID -19): Lessons from Severe Acute Respiratory Syndrome and Middle East Respiratory Syndrome.American Journalof Roentgenology.2020; 214(5):1078-1082.

6. Pattanakuhar S., Suksathien R., Thirapatarapong W. Recommendations for preparedness of Medical Rehabilitation services in Thailand during COVID-19 outbreak. ASEAN Journal of Rehabilitation Medicine. 2020;30 (1):1-7.

7. Thomas P, Baldwin C, Bissett B, Boden I, Gosselink R, Granger CL, et al. Physiotherapy management for COVID-19 in the acute hospital setting: Recommendations to guide clinical 
practice.2020.Available at www.apta.org/

uploadedFiles/APTAorg/

News_and_Publications/ Latest_News/

News_Items/2020/Physiotherapy_

Guideline_COVID-19.pdf. Accessed May 4, 2020.

8. Lazzeri M., Lanza A., Bellini R. et al.

Respiratory physiotherapy in patients with

COVID-19 infection in acute setting: a Proper

Paper of the Italian Association of Respiratory

Physiotherapists (ARIR).Monaldi Archives for

Chest Disease 2020. 2020; 90(1285).

9. IIUMMC Official Channel. Panduan Senaman

Pernafasan Untuk Pesakit [video file]. April 14

2020. [Cited 2020 July 23]. Available from:

https: / /www.youtube.com/watch?v=-

Ztj85xecqY\&t=28s.

10. Smith A.C., Thomas E., Snoswell C.L. et al.

Telehealth for global emergencies: Implication for coronavirus disease 2019 (COVID-19).

Journal of Telemedicine and Telecare. 2020; 0

(0): $1-5$.

11. Goodridge D. and Marciniuk D. Rural and remote care: Overcoming the challenge of distance. Chronic Respiratory Disease. 2016; 13 (2):192-203. 